\title{
Review of molecular methods for identification, characterization and detection of bifidobacteria
}

\author{
Pierre WARD ${ }^{\mathrm{a} *}$, Denis ROY ${ }^{\mathrm{b}}$ \\ a Agriculture and Agri-Food Canada, Food Research and Development Centre, \\ Saint-Hyacinthe, Quebec, Canada \\ ${ }^{b}$ Institute of Nutraceuticals and Functional Foods and Centre STELA, Laval University, \\ Quebec City, Quebec, Canada
}

\begin{abstract}
Final identification of bifidobacteria based on phenotypic patterns (carbohydrate fermentation and enzymatic activity) can be difficult. The distinction between different species or strains of bifidobacteria such as Bifidobacterium longum and Bifidobacterium infantis or Bifidobacterium animalis and Bifidobacterium lactis is not reliable with the phenotypic identification. DNADNA hybridization, ribotyping, hybridization with a specific probe and sequence analysis of 16S rDNA were the first molecular methods used to identify bifidobacteria isolated from commercial products and the gastrointestinal tract. Now, a new group of molecular methods exist for the genus, species and strains identification. The PCR, multiplex PCR, amplified ribosomal DNA restriction analysis (ARDRA), sequencing of specific genes ( $r e c \mathrm{~A}, l d h, h s p 60$ and pyruvate kinase) and denaturing gradient gel electrophoresis (DGGE) are used for the detection, characterization and genus or species identification. Other molecular methods such as pulsed-field gel electrophoresis (PFGE), random amplification of polymorphic DNA (RAPD) and the rep-PCR are used for typing strains of bifidobacteria. Real-time PCR or Q-PCR will be soon an interesting tool for the detection, identification and quantification of bifidobacteria in different samples and commercial products. With new molecular techniques it is easier now to have reliable identification, typing and quantification of bacteria such as Bifidobacterium spp.
\end{abstract}

human bifidobacteria / Bifidobacterium / molecular methods / identification / characterization / detection

Résumé - Revue des méthodes de biologie moléculaire pour la détection, l'identification et la caractérisation des bifidobactéries d'origine humaine et commerciale. Une identification finale basée uniquement sur des tests phénotypiques (fermentation des sucres et activité enzymatique) peut être difficile et la distinction entre certaines espèces comme Bifidobacterium longum et Bifidobacterium infantis ou Bifidobacterium animalis et Bifidobacterium lactis est pratiquement impossible. L'hybridation ADN-ADN, les profils polymorphiques de restriction (RFLP), l'hybridation avec des sondes spécifiques et le séquençage de l'ADNr16S étaient les premières méthodes moléculaires utilisées pour identifier les bifidobactéries. La PCR, la PCR-multiplex, l'analyse de profils de restriction des ADNr16S (ARDRA), le séquençage de gènes spécifique (rec $\mathrm{A}$, ldh, hsp 60 et pyruvate kinase) et l'électrophorèse sur gel avec gradient dénaturant (DGGE) sont maintenant utilisés pour la détection, la caractérisation et l'identification au genre et à l'espèce. D'autres méthodes moléculaires comme l'électrophorèse sur gel en champ pulsé (PFGE), l'amplification aléatoire de l'ADN polymorphe (RAPD), et la rep-PCR peuvent être utilisées pour caractériser à la souche les bifidobactéries. La PCR en temps réel sera prochainement un outil intéressant et performant pour la détection,

\footnotetext{
* Corresponding author: wardp@agr.gc.ca
} 
l'identification et la quantification des bifidobactéries dans différents types d'échantillons ou de produits commerciaux. Avec les nouvelles techniques moléculaires il est maintenant plus facile d'avoir une identification, une caractérisation et une quantification fiable des souches de Bifidobacterium.

bifidobactéries d'origine humaine / Bifidobacterium / méthodes moléculaires / détection / identification / caractérisation

\section{INTRODUCTION}

Bifidobacterium spp. constitute an important class of organisms in the intestinal microflora of healthy children and adults. Among the thirty bifidobacteria species, eleven have been isolated from human until now (Tab. I). There is an evolution in the intestinal microflora, the microorganisms including Bifidobacterium species change with the people's age [3, 29]. The most frequent Bifidobacterium species isolated in infants fecal sample are B. bifidum, B. longum, $B$. infantis and $B$. breve. In adults these species are $B$. adolescentis, $B$. longum, $B$. bifidum and B. catenulatum/B. pseudocatenulatum [25, 26, 45].

It is known that Bifidobacterium can have some beneficial effects on human health. These principal effects are: (1) stimulation of immune response, (2) reduction of growth of many potential pathogens and putrefactive bacteria, (3) prevention of constipation, diarrhea and other intestinal infections, (4) improvement of lactose-tolerance and (5) Bifidobacterium spp. could be used to restore the intestinal microflora after an antibiotic treatment [24, 29, 33].

The probiotic effect of Bifidobacterium explains the popularity of these bacteria in different commercial products. Bifidobacterium species frequently used in probiotic products are $B$. longum, $B$. breve, $B$. bifidum, B. infantis and B. lactis [26]. Yogurt, sour cream, cheese desserts, ice cream and powdered milk are some dairy products that sometimes contain Bifidobacterium [13]. The majority of strains isolated from dairy products were identified as $B$. animalis and were closely related ATCC 27536 [38]. Finally, some strains of $B$. breve, $B$. infantis and B. longum are included in VSL-3 [2], this product is used in the treatment of inflammatory bowel diseases.

Table I. Bifidobacterial species isolated in human and species used in commercial products.

\begin{tabular}{|c|c|}
\hline Species isolated in human & Species used in commercial products \\
\hline B. adolescentis & B. animalis $b$ \\
\hline B. angulatum & B. bifidum \\
\hline B. bifidum & B. breve \\
\hline B. breve & B. infantis ${ }^{a}$ \\
\hline B. catenulatum & B. lactis $b$ \\
\hline B. dentium & B. longum ${ }^{a}$ \\
\hline \multicolumn{2}{|l|}{ B. gallicum } \\
\hline \multicolumn{2}{|l|}{ B. infantis ${ }^{a}$} \\
\hline \multicolumn{2}{|l|}{ B. longum ${ }^{a}$} \\
\hline \multicolumn{2}{|l|}{ B. pseudocatenulatum } \\
\hline B. scardovii & \\
\hline
\end{tabular}

${ }^{a}$ Unification of Bifidobacterium infantis and Bifidobacterium suis as Bifidobacterium longum, this latter species can be divided into three biovars, namely the Infantis biovar, the Longum biovar and the Suis biovar [38].

${ }^{b}$ Reclassification of Bifidobacterium animalis as Bifidobacterium animalis subsp. animalis subsp. nov. and Bifidobacterium lactis as Bifidobacterium animalis subsp. lactis subsp. nov. [23]. 
A right identification of these microorganisms is important for the producers of probiotic products. They have needed to select some bacteria which are usually present in human intestine and these bacteria must be also non-pathogenic and not have adverse effects of any sort. In the majority of laboratories, the phenotypic tests are the principal tools for identification of bacteria. Carbohydrate fermentation, cell wall analysis and detection of specific enzymes are generally used. But, these identification methods require a large amount of time and do not always give clear results $[10,14,26]$. For example, the distinction between some species currently used in commercial products such as $B$. infantis and $B$. longum, or $B$. animalis and $B$. lactis is difficult when phenotypic tests are only used [23, 37, 38]. To help microbiologists, researchers and producers to do the right identification and characterization of bacteria including Bifidobacterium some molecular methods have been developed. A review of these methods will be described in this paper.

\section{THE FIRST MOLECULAR METHODS USED}

The first molecular identification methods developed were DNA-DNA hybridization, sequence analysis of $16 \mathrm{~S}$ rDNA, hybridization with a specific probe and RFLP analysis or ribotyping. In contrast to physiological and biochemical characteristics, the molecular identification is based on the constitutive composition of nucleic acids rather than on the products of their expression. These molecular methods are often used in association with the conventional microbiological identification. With DNA-DNA hybridization, percent homology between the test strain and the reference strain can be determined in using membrane filter for the DNA fixation and radioisotopes for detection $[4,41]$, or using microplate and photobiotin $[6,40,52]$. When the percentage of homology is higher than $70 \%$ between the isolated and the reference strain, and the phenotypic criteria agree with the species definition, these strains can be grouped together in the same species [14, 16, 51]. Homology between $B$. longum and $B$. infantis is often near $70 \%$ [14] and with $B$. animalis and $B$. lactis this homology is higher than $80 \%$ between the type strain of $B$. lactis and $B$. animalis strains [26]. These results confirm the similarity between $B$. longum and B. infantis and the confusion with $B$. lactis species.

The 16S rRNA gene is considered to be universally present in bacteria and shows a high degree of sequence conservation. The sequence homology analysis of this gene demonstrates some interesting results for the phylogenetic analysis of the genus Bifidobacterium [8, 21]. However, sequence similarities are very high with some species groups: B. catenulatum and B. pseudocatenulatum group (similarity $99.5 \%$ ), B. longum and $B$. infantis group (similarity $99.1 \%$ ), $B$. lactis and $B$. animalis group (similarity $99 \%)[28,30]$. Recently, the unification of $B$. infantis, $B$. longum and $B$. suis divided in three biotypes and the separation of $B$. lactis from $B$. animalis at the subspecies level have been proposed [23, 39, 46].

For the hybridization with a specific probe, the nucleic acid is fixed on a solid support, nitrocellulose or nylon membrane, by dot blot or colony hybridization $[15,17]$. The probe can be a single oligonucleotide or cloned and characterized DNA fragment, labeled with biotin or digoxigenin to produce a colorimetric reaction [17] or radiolabeled [15, 53]. With the radiolabeled probes the amount of hybrid formed is determined by autoradiography. Fluorescence in-situ hybridization (FISH) on a microscopic slide was also used to detect and to determine the population of Bifidobacterium spp. in different samples [12, 20]. Some genus-specific and species-specific probes for $B$. adolescentis, B. pseudocatenulatum, B. bifidum, B. breve, B. animalis, and $B$. longum were proposed $[3,15,53]$.

Ribotyping or restriction fragment length polymorphism (RFLP) of genes coding for rRNA uses a labeled probe containing $16 \mathrm{~S}$ or $23 \mathrm{~S}$ or both 16 and 23 ribosomal cDNA. Before hybridization the DNA is digested with BamHI, EcoRV, PvuII or NarI [22, 27] and transferred on a membrane by Southern blot. The hybridization patterns or ribotypes produced by hybridization of probe to different fragments of DNA digested allow to do the differentiation between the following 
species B. adolescentis, B. animalis, B. bifidum, B. breve, B. infantis and B. longum [27].

\section{THE NEW GENERATION OF MOLECULAR METHODS}

The PCR discovery, the new cloning, sequencing and fluorescence detection technology and the accessibility of a large quantity of information on the web helped the development of new molecular tools. The second generation of molecular methods for genus and species detection and identification are polymerase chain reaction (PCR), multiplex-PCR, sequencing of specific genes, amplified ribosomal DNA restriction analysis and denaturing gradient gel electrophoresis (DGGE).

\subsection{Polymerase chain reaction (PCR)}

The PCR is a fast, accurate, sensitive and easy operating technique. The amplification of bifidobacterial DNA directly extracted from a colony or a faecal sample, without prior culture, can be done [18, 31]. PCR inhibitors from faecal sample could be removed with some washing steps with buffers before breaking the bacterial cells. Instead of faecal samples, dairy products and bacterial culture can be used [26]. Bile salts and complex polysaccharides can also inhibit or reduce the amplification efficiency [2]. Another advantage of this technique for Bifidobacterium detection is that the PCR does not require anaerobic conditions compared to the classical culture method [26]. The amplification of a specific DNA fragments or a complete gene can be done with the PCR. The specificity of this technique is directly associated with the primers selection and the primers annealing temperature. Some primer pairs based on 16S rDNA sequences or on $16 \mathrm{~S}$ to $23 \mathrm{~S}$ internal transcribed spacer sequences, are selected for the detection of Bifidobacterium genus and for the principal human species (B. bifidum, $B$. breve, $B$. infantis, $B$. longum, B. adolescentis, $B$. angulatum, $B$. catenulatum group, $B$. dentium, and B. gallicum) $[24,25,38,43,50]$ and strains used in commercial products (B. lactis and B. animalis) $[35,47]$.

\subsection{Multiplex PCR}

Multiplex PCR is similar to the conventional PCR. Many primer pairs are used in the same reaction at the same time, to the detection of many bacterial genus or different species. Others advantages of this technique are the reduction of the number of PCR reactions and the reduction of the time spent. With this method it's very important to keep in mind the following recommendations: (1) annealing primer temperature for all primers are needed to be in the same range; (2) primers used could not give any cross-reaction under multiplex conditions; (3) different PCR product sizes are necessary to be able to do the distinction between the different species or bacteria; and (4) this technique needed a larger amount of Taq polymerase than is used in conventional PCR [26]. Different multiplex have been designed for simultaneously detection of (1) B. bifidum, B. breve, B. infantis, B. longum, B. adolescentis [5], (2) B. bifidum, B. breve, $B$. infantis, (3) B. angulatum, B. catenulatum/B. pseudocatenulatum continuum, $B$. dentium, B. longum and (4) B. adolescentis, B. scardovii, B. gallicum [31]. The multiplex 1 was designed with specific primers based on $16 \mathrm{~S}$ to $23 \mathrm{~S}$ internal spacer sequences [5]. Some cross-reaction of $B$. suis with both $B$. infantis and $B$. longum primers based on $16 \mathrm{~S}$ rDNA used in multiplex 2 and 3 have been observed [31].

\subsection{Sequences of specific genes}

Sequences of specific genes can be used for identification and characterization of Bifidobacterium. It's known that the DNA sequences of protein-coding genes are more effective than 16S rRNA gene sequencing for the characterization of Bifidobacterium species $[16,19,37]$. Some genes other than the 16S rRNA are used for the differentiation of bifidobacteria. These genes are: L-lactate deshydrogenase gene (ldh), recA gene, $60 \mathrm{~kg} \cdot \mathrm{mol}^{-1}$ heat shock protein (HSP60) gene, Pyruvate kinase (PK) gene $[16,19,37,44]$. Before sequencing, a part 
of gene is selected and amplified by PCR. The PCR product is sequenced, analyzed and compared with other sequences. With a short region of the rec $\mathrm{A}(231 \mathrm{bp})$ and $l d h$ (312 bp) gene it is possible to distinguish between the principal human species $B$. bifidum, $B$. infantis, $B$. longum, $B$. adolescentis, $B$. breve and $B$. animalis strains frequently used in commercial products [19, 37]. Also, the analysis of a region of the $l d h$ gene showed that nucleotide sequence of $B$. lactis DSM 10140 and B. animalis ATCC 27536 were identical but different between B. lactis DSM 10140 and B. animalis ATCC $25527^{\mathrm{T}}$ [37]. Partial pyruvate kinase gene (300 bp) allows differentiating $B$. infantis from $B$. longum and also $B$. animalis from B. lactis [44]. Finally, analysis of partial hsp60 gene (538 bp) sequences is very effective for the differentiation between all human Bifidobacterium species. Sequence similarity is $93 \%$ between $B$. catenulatum and $B$. pseudocatenulatum, $98 \%$ between B. longum, B. infantis and B. suis and $98 \%$ between $B$. animalis and $B$. lactis [16]. The hsp60 gene is a powerful tool for the phylogenetic study of Bifidobacterium species, this gene has a power higher than the $16 \mathrm{~S}$ rRNA gene. So, the differentiation of the principal human bifidobacteria species after sequencing and alignment of a short sequence of a specific gene is possible. And the differentiation between $B$. lactis and B. animalis can be done with $h s p 60$ and pyruvate kinase gene [16, 44].

\subsection{Amplified ribosomal DNA restriction analysis (ARDRA)}

Bacterial culture and DNA isolation are needed with the amplified ribosomal DNA restriction analysis (ARDRA) technique. The DNA is used to the PCR amplification of the totality or only a region of the $16 \mathrm{~S}$ rRNA gene. This amplification is followed by a restriction digestion of the PCR products. The selection of restriction enzymes is important to have a clear distinction in ARDRA pattern to differentiate the larger amount of species. The digestion products are visualised under UV-light after agarose gel electrophoresis and ethidium bromide staining. Analysis and comparison of more than one restriction profile can be necessary to have a differentiation between some close species. A first study by Roy and Sirois [37], demonstrate the differentiation between B. animalis, B. longum, B. infantis, $B$. breve, B. bifidum and B. adolescentis after an amplification of $914 \mathrm{bp}$ region of the 16S rRNA gene and restriction with BamHI, Sau3AI and TaqI. The restriction pattern from $B$. lactis strains was identical to that of the $B$. animalis strains. B. longum was closely related to $B$. infantis but differentiation between these two species was obtained with the Sau3A1 restriction enzyme. Some similar results were obtained by Ventura et al. [48] after the restriction of the complete 16S rRNA gene with BamHI and Sau3AI. However, this team demonstrated the possibility to also differentiate $B$. catenulatum and B. pseudocatenulatum with these patterns. Another study by Venema and Maathuis [45] showed the differentiation between all the Bifidobacterium species found in human alimentary tract, including $B$. lactis and $B$. animalis. This differentiation was done with a combination of six restriction patterns from a 511 to $525 \mathrm{bp} 16 \mathrm{~S}$ ribosomal gene fragment with the following enzymes TaqI, Sau3AI, RsaI, AluI, Sau96I and NciI. ARDRA system is a good and reproducible molecular identification tool for human Bifidobacterium species. With this method the differentiation between $B$. infantis and $B$. longum or between B. catenulatum and B. pseudocatenulatum is possible [37, 45, 48]. NciI enzyme is used to do the distinction between $B$. animalis and B. lactis [45].

\subsection{Denaturing gradient gel electrophoresis (DGGE)}

Denaturating gradient gel electrophoresis is based on the discontinuous phenomenon of strand dissociation, allows the resolution of DNA fragments differing by as little as a single nucleotide substitution. The principal difficulties with the DGGE are to choose the right running time and gel conditions to achieve the optimal separation. For DGGE analysis of PCR products a GC clamp is attached to the 5' end to either of the primers. But, the efficiency of the separation 
can be different if the GC clamp is attached to the forward or the reverse primer [40]. Also, some closely related species like $B$. infantis and B. longum or B. catenulatum and $B$. pseudocatenulatum could not be separated from each other by this approach and the primer Bif164-f and Bif662-r specific for a $16 \mathrm{~S}$ rDNA region [40]. The PCR amplification of the V2-V3 regions of the $16 \mathrm{~S}$ rDNA or transaldolase DNA fragment followed by DGGE allow the separation of $B$. animalis, $B$. lactis, $B$. bifidum, $B$. infantis, B. longum, B. adolescentis, B. pseudocatenulatum and $B$. breve $[7,36]$. In the PCR-DGGE approach identification of fragment can be confirmed by subsequent cloning and sequencing of the PCR products. This method is popular to evaluate the bacterial composition in fecal samples $[37,40]$ and can be an interesting and rapid method for the screening of the bifidobacterial composition of probiotic products [7].

\section{MOLECULAR METHODS FOR SPECIES OR STRAINS IDENTIFICATION AND CHARACTERIZATION}

These tools are very interesting to identify and characterize Bifidobacterium strains in commercial products and in the intestinal tract. These typing methods are principally: Random Amplified Polymorphic DNA (RAPD), Pulsed-Field Gel Electrophoresis (PFGE) and rep-PCR. Strains differentiation is possible with these techniques, but, it is impossible to be sure that some strains are the same only based on identical pattern, if the history of strains is unknown.

\subsection{Random Amplified Polymorphic DNA (RAPD)}

The Random Amplified Polymorphic DNA (RAPD) is frequently used to characterize probiotic bacteria. With this technique, the entire genome extracted from a bacterial culture is used to generate the DNA profile after PCR amplification with random primers $[9,39,49]$. These primers are often 10 nucleotides and only one is used in each reaction. The different size amplicons were visualised under UV-light after agarose gel electrophoresis and ethidium bromide staining. RAPD profiles can be combined and analysed with appropriate software. The advantage of RAPD is that it allows to distinguish strains within species that cannot be differentiated by ARDRA. Vincent et al. [49] used OPA-02, OPA-18, OPL-07, OPL-16 and OPM-05 primers to group in for different clusters $B$. breve, $B$. adolescentis, $B$. bifidum and B. animalis. Strains of $B$. infantis were grouped into a subcluster of B. longum. The similar results were obtained by Sakata et al. [39] with $B$. infantis, B. longum and B. suis. The comparison of RAPD profiles can also be used to recover a specific strain in different samples. Variation between species and strains could be identified with the number and size of DNA fragments. Sometimes the reproducibility of this technique is low and the utilization of control conditions and meticulous handling is needed. Finally, RAPD profiles may be altered by the presence of transposable elements or plasmids [49].

\subsection{Pulsed-Field Gel Electrophoresis (PFGE)}

A good reproducibility and efficient differentiation between Bifidobacterium strains is observed with this electrophoresis method. Compared to the others molecular techniques, the pulsed-field gel electrophoresis (PFGE) require a large amount of time and genomic DNA extraction in agarose block is necessary. This extraction allows to keep the DNA intact before the digestion. Rare cutting restriction enzymes could be selected to obtain a DNA profile containing 10 to 20 fragments. Periodical change in the electrical field orientation during 18 to $24 \mathrm{~h}$ migration allows the separation of large DNA fragments. With Bifidobacterium strains XbaI, SpeI, DraI and AseI are four enzymes generating selective patterns [1, $11,32,35,38]$. PFGE profiles were obtained with some commercial $[11,38]$ and reference strains of $B$. animalis, $B$. infantis, $B$. longum, B. bifidum, B. adolescentis, $B$. angulatum, $B$. catenulatum, $B$. pseudocatenulatum, $B$. lactis and $B$. breve $[1,32,35$, 38]. These profiles are generally different 
between the different strains. However, B. animalis ATCC 25527 and ATCC 27674 have the same PFGE pattern after digestion with XbaI and SpeI [38], B. animalis ATCC 27536 and B. lactis DSM 10140 have also the same profile. The majority of Bifidobacterium strains isolated from European commercial preparations cannot be distinguished from B. animalis ATCC 27536, previously isolated from chicken feces [38]. PFGE can also be used to estimate the genome size. Some big variations were observed in genome size of some strains belonging to the same species. For example with B. bifidum the estimated size after digestion with $X b a \mathrm{I}$ were between 1.6 to $2.2 \mathrm{Mb}$ [38]. Estimated Bifidobacterium genome size ranged between 1.1 to $2.2 \mathrm{Mb}[1,32,38]$.

\section{3. rep-PCR}

Another method to obtain genomic DNA fingerprinting of bifidobacteria is the repPCR. This PCR uses primers to match short consensus repetitive sequences. Three different primers can be used namely BOX (originally described in Streptococcus pneumoniae). ERIC (originally described in Salmonella typhimurium) and REP (originally described in Escherichia coli) [10]. Differences in band sizes represent polymorphisms in the distance between the repetitive elements of different strains. Presently some study using BOX and ERIC primers for the characterization and differentiation of Bifidobacterium strains have been published $[10,42,46]$. With ERIC primer, it is possible to distinguish five different species of bifidobacteria (B. pseudocatenulatum, B. infantis, $B$. longum, $B$. animalis and $B$. indicum) [42]. This technique is also applicable to differentiate different strains in a same species. Furthermore, ERIC-PCR demonstrated that some strains of B. lactis and B. animalis (ATCC 27536, ATCC 27673 and ATCC 27674) were not comparable to any other B. animalis strains [46]. These observations confirm the results obtained by Roy et al. [37] with the sequences of $l d h$ gene and the PFGE patterns. The differentiation of $B$. breve, B. bifidum, B. longum, B. infantis and $B$. adolescentis can also be done with BOX-PCR [10].

\section{FUTURE PERSPECTIVES}

Real-time PCR or Quantitative-PCR is effective for the detection and quantification of microorganisms in the same reaction. It is more sensitive than the conventional PCR and the amplification of PCR product is detected at each cycle. With the RealTime PCR the fluorescence is used for the detection of PCR product. SYBR Green and fluorescing probes like Taqman probe are presently the most popular tools for the detection in real-time PCR. The fluorescing probes are more specific than the SYBR Green and with these probes it is possible to perform multiplex reaction. However, some specific conditions, like G-C percent, melting temperature, probe length, etc., must be respected for the construction of probes. In the reaction with SYBR Green the primers are mixed with the dye, while the DNA is extended by DNA polymerase, the SYBR Green is incorporated between the double-stranded DNA and the amplicon is detected. The fluorescence is a thousand times higher when the SYBR Green is fixed to the DNA compared to the free molecules in PCR reaction solution. With the Taqman probe, there is at each extremity of the probe a fluorochrome and a suppressor (quencher). In this PCR reaction, the primers and the probe fix the target and during the DNA extension the Taq DNA polymerase hydrolyse the probe, the fluorochrome (reporter) is separated to the suppressor or the quencher and there is light emission. Molecular Beacons probes and scorpion primer will be the next detection tools in real time PCR [34].

Presently the Real-Time PCR targeting the transaldolase gene can be used to detect and enumerate bifidobacteria in fecal samples [37]. Comparison of bifidobacterial count obtained by culture and real-time PCR showed a good correlation [26, 36]. This technique could be used to detect different Bifidobacterium species with some probes based on $h s p 60$ gene and could also be used in multiplex to the detection of some Bifidobacterium species simultaneously in the same product.

Amplified restriction fragment polymorphism (AFLP) could be also an interesting technique for the characterization of 
bifidobacteria. This technique is based on the selective amplification of restriction fragments from a total digest of genomic DNA. AFLP combines two strategies generally used in DNA fingerprinting: (1) the hybridization-based fingerprinting involving the cutting of genomic DNA with restriction endonuclease and (2) the PCR-based fingerprinting involving the amplification of particular DNA sequences using specific or arbitrary primers. The AFLP is highly sensitive and considered, along with the PFGE, as the most discriminating genotypic technique [23].

\section{CONCLUSION}

There are many molecular methods for the identification, characterization and detection of Bifidobacterium and many of these techniques are based on the $16 \mathrm{~S}$ ribosomal gene. PCR and ARDRA are two easy and sensitive methods for the detection and identification of Bifidobacterium genus and species. The most accurate method for differentiation at the strain level is the PFGE, but it is impossible to be sure that some strains are the same only with an identical pattern. The distinction between some closely related Bifidobacterium species like $B$. infantis and B. longum, B. catenulatum and $B$. pseudocatenulatum or B. lactis and $B$. animalis is possible with some molecular tools. But, the unification of $B$. infantis $B$. longum and $B$. suis divided in three biotypes and the separation of $B$. lactis from $B$. animalis at the subspecies level are proposed $[23,39,46]$. And finally, in the future Real-Time PCR will be very popular for the detection, identification and quantification of Bifidobacterium spp.

\section{REFERENCES}

[1] Bourget N., Simonet J.M., Decaris B., Analysis of the genome of the five Bifidobacterium breve strains: plasmid content, pulsed-field gel electrophoresis genome size estimation and $r r n$ loci number, FEMS Microbiol. Lett. 110 (1993) 11-20.

[2] Brigidi P., Swennen E., Vitali B., Rossi M., Matteuzi D., PCR detection of Bifidobacterium strains and Streptococcus thermophilus in feces of human subjects after oral bacteriotherapy and yogurt consumption, Int. J. Food Microbiol. 81 (2003) 203-209.

[3] Charteris W.P., Kelly P.M., Morelli L., Collins J.K., Selective detection, enumeration and identification of potentially probiotic Lactobacillus and Bifidobacterium species in mixed bacterial populations, Int. J. Food Microbiol. 35 (1997) 1-27.

[4] Crociani F., Biavati B., Alessandrini A., Chiarini C., Scardovi V., Bifidobacterium inopinatum sp. nov. and Bifidobacterium denticolens sp. nov., two new species isolated from human dental caries, Int. J. Syst. Bacteriol. 46 (1996) 564-571.

[5] Dong X., Cheng G., Jian W., Simultaneous identification of five Bifidobacterium species isolated from human beings using multiple PCR primers, Syst. Appl. Microbiol. 23 (2000) 386-390.

[6] Ezaki T., Hashimoto Y., Yabuuchi E., Fluorometric deoxyribonucleic acid hybridization in microdilution well as an alternative to membrane filter hybridization in which radioisotopes are used to determine genetic relatedness among bacterial strains, Int. J. Bacteriol. 39 (1989) 224-229.

[7] Fasoli S., Marzotto M., Rizzotti L., Rossi F., Dellaglio F., Torriani S., Bacterial composition of commercial probiotic products as evaluated by PCR-DGGE analysis, Int. J. Food Microbiol. 82 (2003) 59-70.

[8] Frothingham R., Duncan A.J., Wilson K.H., Ribosomal DNA sequences of bifidobacteria: Implication for sequence-based identification of the human colonic flora, Microb. Ecol. Health Dis. 6 (1993) 23-27.

[9] Fujiwara S., Seto Y., Kimura A., Hashiba H., Intestinal transit of an orally administered streptomycin-rifampicine-resistant variant of Bifidobacterium longum SBT2928: its longterm survival and effect on the intestinal microflora and metabolism, J. Appl. Microbiol. 90 (2001) 43-52.

[10] Gomez Zavaglia A., de Urraza P., De Antoni G., Characterization of Bifidobacterium strains using box primers, Anaerobe. 6(2000) 169-177.

[11] Grand M., Küffer M., Baumgartner A., Quantitative analysis and molecular identification of bifidobacteria strains in probiotic milk products, Eur. Food Res. Technol. 217 (2003) 90-92.

[12] Harmsen H.J.M., Gibson G.R., Elfferich P., Raangs G.C., Wildeboer-Veloo A.C.M., Argaiz A., Roberfroid M.B., Welling G.W., Comparison of viable cell counts and fluorescence in situ hybridization using specific rRNAbased probes for the quantification of human fecal bacteria, FEMS Microbiol. Lett. 183 (1999) 125-129. 
[13] Hawkins S.M., Bifidobacteria in dairy products, Cult. Dairy Prod. J. 28 (1993) 16-20.

[14] Herreman C., Asselin D., Novel G., Identification et caractérisation de souches industrielles du genre Bifidobacterium par 2 méthodes de taxonomie moléculaire, Lait. 74 (1994) 479-484.

[15] Ito M., Ohno T., Tanaka R., A specific DNA probe for identification of Bifidobacteriun breve, Microb. Ecol. Health Dis. 5 (1992) 185-192.

[16] Jian W., Zhu L., Dong X., New approach to phylogenetic analysis of the genus Bifidobacterium based on partial HSP60 gene sequences, Int. J. Syst. Evol. Microbiol. 51 (2001) 1633-1638.

[17] Kaufmann P., Pfefferkorn A., Teuber M., Meile L., Identification and quantification of Bifidobacterium species isolated from food with genus-specific 16S rRNA-targeted probes by colony hybridization and PCR, Appl. Environ. Microbiol. 63 (1997) 1268-1273.

[18] Kullen M.J., Amann M.M., O’Shaughnessy M.J., O'Sullivan D.J., Busta F.F., Brady L.J., Differentiation of ingested and endogenous bifidobacteria by DNA fingerprinting demonstrates the survival of an unmodified strain in the gastrointestinal tract of humans, J. Nutr. 127 (1997) 89-94.

[19] Kullen M.J., Brady L.J., O’Sullivan D.J., Evaluation of using a short region of the rec $\mathrm{A}$ gene for rapid and sensitive speciation of dominant bifidobacteria in the human large intestine, FEMS Microbiol. Lett. 154 (1997) 377-383.

[20] Langendijk P.S., Schut F., Jansen G.J., Raangs G.C., Kamphuis G.R., Wilkinson H.F., Welling G.W., Quantitative fluorescence in situ hybridization of Bifidobacterium $\mathrm{spp}$. with genus-specific $16 \mathrm{~S}$ rRNA-targeted probes and its application in fecal samples, Appl. Environ. Microbiol. 61 (1995) 3069-3075.

[21] Leblond-Bourget N., Philippe H., Mangin I., Decaris B., 16S rRNA and 16S to $23 \mathrm{~S}$ internal transcribed spacer sequence analyses reveal inter- and intraspecific Bifidobacterium phylogeny, Int. J. Syst. Bacteriol. 46 (1996) 102-111.

[22] Mangin I., Bourget N., Bouhnik Y., Bisetti N., Simonet J.M., Decaris B., Identification of Bifidobacterium strains by rRNA gene restriction patterns, Appl. Environ. Microbiol. 60 (1994) 1451-1458.

[23] Masco L., Ventura M., Zink R., Huys G., Swings J., Polyphasic taxonomic analysis of Bifidobacterium animalis and Bifidobacterium lactis reveals relatedness at the subspecies level: reclassification of Bifidobacterium animalis as Bifidobacterium animalis subsp. animalis subsp. nov. and Bifidobacte- rium lactis as Bifidobacterium animalis subsp. lactis subsp. nov, Int. J. Syst. Evol. Microbiol. 54 (2004) 1137-1143.

[24] Matsuki T., Watanabe K., Tanaka R., Oyaizu H., Rapid identification of human intestinal bifidobacteria by $16 \mathrm{~S}$ rRNA-targeted species- and group-specific primers, FEMS Microbiol. Lett. 167 (1998) 113-121.

[25] Matsuki T., Watanabe K., Tanaka R., Fukuda M., Oyaizu H., Distribution of bifidobacterial species in human intestinal microflora examined with $16 \mathrm{~S}$ rRNA-gene-targeted species-specific primers, Appl. Environ. Microbiol. 65 (1999) 4506-4512.

[26] Matsuki T., Watanabe K., Tanaka R., Genusand species-specific PCR primers for the detection and identification of bifidobacteria, Curr. Issues Intest. Microbiol. 4 (2003) 6169.

[27] McCartney A.L., Tannock G.W., Ribotyping of Bifidobacterium strains using cells embedded in agarose plugs and a $16 \mathrm{~S}$ rDNA probe, Microb. Ecol. Health Dis. 8 (1995) 79-84.

[28] Meile L., Ludwig W., Rueger U., Gut C., Kaufmann P., Dasen G., Wenger S., Teuber M., Bifidobacterium lactis sp. nov., a moderately oxygen tolerant species isolated from fermented milk, System. Appl. Microbiol. 20 (1997) 57-64.

[29] Mitsuoka T., Bifidobcteria and their role in human health, J. Indust. Microbiol. 6 (1990) 263-268.

[30] Miyake T., Watanake K., Watanake T., Oyaizu H., Phylogenetic analysis of the genus Bifidobacterium and related genera based on the 16S rDNA sequences, Microbiol. Immunol. 42 (1998) 661-667.

[31] Mullié C., Odou M.F., Singer E., Romond M.B., Izard D., Multiplex PCR using 16S rRNA gene-targeted primers for the identification of bifidobacteria from human origin, FEMS Microbiol. Lett. 222 (2003) 129-136.

[32] O’Riordan K., Fitzgerald G.F., Determination of genetic diversity within the genus Bifidobacterium and estimation of chromosomal size, FEMS Microbiol. Lett. 156 (1997) 259-264.

[33] O’Sullivan D.J., Kullen M.J., Tracking of probiotic bifidobacteria in the intestine, Int. Dairy J. 8 (1998) 513-525.

[34] Poitras E., Houde A., La PCR en temps réel : principes et applications, Rev. Biol. Biotechnol. 2 (2002) 2-11.

[35] Prasad J., Gill H., Smart J., Gopal P.K., Selection and characterization of Lactobacillus and Bifidobacterium strains for use as probiotics, Int. Dairy J. 8 (1998) 993-1002.

[36] Requena T., Burton J., Matsuki T., Munro K., Simon M.A., Tanaka R., Watanabe K., Tannock G.W., Identification, detection and enumeration 
of human Bifidobacterium species by PCR targeting the transaldolase gene, Appl. Environ. Microbiol. 68 (2002) 2420-2427.

[37] Roy D., Sirois S., Molecular differentiation of Bifidobacterium species with amplified ribosomal DNA restriction analysis and alignment of short regions of the $l d h$ gene, FEMS Microbiol. Lett. 191 (2000) 17-24.

[38] Roy D., Ward P., Champagne G., Differentiation of bifidobacteria by use of pulsed-field gel electrophoresis and polymerase chain reaction, Int. J. Food Microbiol. 29 (1996) 11-29.

[39] Sakata S., Kitahara M., Sakamoto M., Hayashi H., Fukuyama M., Benno Y., Unification of Bifidobacterium infantis and Bifidobacterium suis as Bifidobacterium longum, Int. J. Syst. Evol. Microbiol. 52 (2002) 1945-1951.

[40] Satokari R.M., Vaughan E.E., Akkermans A.D.L., Saarela M., de Vos W.M., Bifidobacterial diversity in human feces detected by genus-specific PCR and denaturing gradient gel electrophoresis, Appl. Environ. Microbiol. 67 (2001) 504-513.

[41] Scardovi V., Crociani F., Bifidobacterium catenulatum, Bifidobacterium dentium and Bifidobacterium angulatum: three new species and their deoxyribonucleic acid homology relationships, Int. J. Syst. Bacteriol. 24 (1974) 6-20.

[42] Shuhaimi M., Ali A.M., Saleh N.M., Yazid A.M., Utilisation of enterobacterial repetitive intergenic consensus (ERIC) sequence-based PCR to fingerprint the genomes of Bifidobacterium isolates and other probiotic bacteria, Biotechnol. Lett. 23 (2001) 731-736.

[43] Silvi S., Verdenelli M.C., Orpianesi C., Cresci A., EU project crownalife: functional foods, gut microflora and healthy ageing. Isolation and identification of Lactobacillus and Bifidobacterium strains from feacal samples of elderly subjects for a possible probiotic use in functional foods, J. Food Eng. 56 (2003) 195-200.

[44] Vaugien L., Prevots F., Roques C., Bifidobacteria identification based on 16S rRNA and pyruvate kinase partial gene sequence analysis, Anaerobe 8 (2002) 341-344.

[45] Venema K., Maathuis A.J.H., A PCR-based method for identification of bifidobacteria from the human alimentary tract at the species level, FEMS Microbiol. Lett. 224 (2003) 143-149.

[46] Ventura M., Zink R., Rapid identification, differentiation, and proposed new taxonomic classification of Bifidobacterium lactis, Appl. Environ. Microbiol. 68 (2002) 6429-6434.

[47] Ventura M., Reniero R., Zink R., Specific identification and targeted characterization of Bifidobacterium lactis from different environmental isolates by a combined multiplexPCR approach, Appl. Environ. Microbiol. 67 (2001) 2760-2765.

[48] Ventura M., Elli M., Reniero R., Zink R., Molecular microbial analysis of Bifidobacterium isolates from different environments by the species-specific amplified ribosomal DNA restriction analysis (ARDRA), FEMS Microbiol. Ecol. 36 (2001) 113-121.

[49] Vincent D., Roy D., Mondou F., Déry C., Characterization of bifidobacteria by random DNA amplification, Int. J. Food Microbiol. 43 (1998) 185-193

[50] Wang R.F., Cao W.W., Cerniglia C.E., PCR detection and quantification of predominant anaerobic bacteria in human and animal fecal samples, Appl. Environ. Microbiol. 62 (1996) 1242-1247.

[51] Wayne L.G., Brenner D.J., Colwell R.R., Report of the ad hoc committee on reconciliation of approaches to bacterial systematics, Int. J. Syst. Bacteriol. 37 (1987) 463-464.

[52] Yaeshima T., Takahashi S., Ishibashi N., Shimamura S., Identification of bifidobacteria from dairy products and evaluation of a microplate hybridization method, Int. J. Food Microbiol. 30 (1996) 303-313.

[53] Yamamoto T., Morotomi M., Tanaka R., Species-specific oligonucleotide probes for five Bifidobacterium species detected in human intestinal microflora, Appl. Environ. Microbiol. 58 (1992) 4076-4079. 